\title{
High Prevalence of Plasmodium falciparum Infection in Asymptomatic Individuals from the Democratic Republic of the Congo
}

\author{
Dieudonné Makaba Mvumbi, ${ }^{1,2}$ Thierry Lengu Bobanga, ${ }^{3}$ Pierrette Melin, ${ }^{2}$ \\ Patrick De Mol, ${ }^{2}$ Jean-Marie Ntumba Kayembe, ${ }^{4}$ Hippolyte Nani-Tuma Situakibanza, ${ }^{3,4}$ \\ Georges Lelo Mvumbi, ${ }^{1}$ Célestin Ndosimao Nsibu, ${ }^{5}$ Solange Efundu Umesumbu, ${ }^{6}$ \\ and Marie-Pierre Hayette ${ }^{2}$ \\ ${ }^{1}$ Biochemistry and Molecular Biology Unit, Department of Basic Sciences, School of Medicine, University of Kinshasa, \\ P.O. Box Kin XI, Kinshasa, Democratic Republic of the Congo \\ ${ }^{2}$ Department of Clinical Microbiology, University Hospital of Liege, 4000 Liege, Belgium \\ ${ }^{3}$ Department of Parasitology and Tropical Medicine, School of Medicine, University of Kinshasa, P.O. Box Kin XI, \\ Kinshasa, Democratic Republic of the Congo \\ ${ }^{4}$ Department of Internal Medicine, School of Medicine, University of Kinshasa, P.O. Box Kin XI, \\ Kinshasa, Democratic Republic of the Congo \\ ${ }^{5}$ Department of Pediatrics, School of Medicine, University of Kinshasa, P.O. Box Kin XI, Kinshasa, Democratic Republic of the Congo \\ ${ }^{6}$ National Malaria Control Program, P.O. Box Kin XI, Kinshasa, Democratic Republic of the Congo \\ Correspondence should be addressed to Dieudonné Makaba Mvumbi; didimvumbi@gmail.com
}

Received 23 September 2015; Revised 20 November 2015; Accepted 29 December 2015

Academic Editor: Sasithon Pukrittayakamee

Copyright (C) 2016 Dieudonné Makaba Mvumbi et al. This is an open access article distributed under the Creative Commons Attribution License, which permits unrestricted use, distribution, and reproduction in any medium, provided the original work is properly cited.

\begin{abstract}
Malaria remains a major public health problem in the Democratic Republic of Congo (DRC) with 14 million cases reported by the WHO Malaria Report in 2014. Asymptomatic malaria cases are known to be prevalent in endemic areas and are generally untreated, resulting in a significant source of gametocytes that may serve as reservoir of disease transmission. Considering that microscopy certainly underestimates the prevalence of Plasmodium infections within asymptomatic carriers and that PCR assays are currently recognized as the most sensitive methods for Plasmodium identification, this study was conducted to weigh the asymptomatic carriage in DRC by a molecular method. Six provinces were randomly selected for blood collection in which 80 to 100 individuals were included in the study. Five hundred and eighty blood samples were collected and molecular diagnosis was performed. Globally, almost half of the samples collected from asymptomatic individuals $(280 / 580 ; 48.2 \%)$ had Plasmodium infections and the most species identified was $P$. falciparum alone in combination with $P$. malariae. The high prevalence reported here should interpellate the bodies involved in malaria control in DR Congo to take into account asymptomatic carriers in actions taken and consider asymptomatic malaria as a major hurdle for malaria elimination.
\end{abstract}

\section{Introduction}

Malaria is a parasitic disease caused by Plasmodium species transmitted to man by a mosquito bite [1]. Four Plasmodium species infect human but Plasmodium falciparum is responsible for the major morbimortality. Infection with $P$. falciparum can result in a simply asymptomatic carriage, uncomplicated or severe malaria. In fact, there is an exposurerelated immunity in malaria that could explain these different expressions [2].

In high transmission settings, symptomatic malaria is often concerning children below five years as they have 
not been for long time exposed to the parasite and asymptomatic infections generally concern adults that acquired an antidisease and/or an antiparasite immunity during their exposure time [3-6]. Asymptomatic malaria cases are known to be prevalent in endemic areas [7-9] and are generally untreated, resulting in a significant source of gametocytes that may serve as reservoir of disease transmission [10].

The Democratic Republic of the Congo (DRC) is the second largest country in Africa and has a population that is estimated to be 75.5 million people. It is estimated that $97 \%$ of the population live in zones with stable transmission. In the WHO malaria report for 2014, 14 million of malaria cases were reported in DRC [11]. Some studies conducted in DRC revealed significant prevalence of asymptomatic Plasmodium carriers. Matangila et al. reported a prevalence of $21.6 \%$, $27.4 \%$, and $29.5 \%$ of asymptomatic $P$. falciparum infection in pregnant women in Kinshasa, respectively, by microscopy, Rapid Diagnostic Tests (RDTs), and PCR [12]. Maketa et al. found a prevalence of Plasmodium infection in asymptomatic children of $30.9 \%$ and $14.3 \%$ in two areas of Kinshasa, based on microscopic identification of thick blood smears [13]. The most recent available data are from a countrywide study that reports a prevalence of Plasmodium infection, in asymptomatic children less than five years, of $23 \%$ and $31 \%$, respectively, determined by microscopy and RDT [14]. But Tiono et al. showed in their work that RDTs have some limits in detecting asymptomatic carriers of P. falciparum [15].

Currently, Polymerase Chain Reaction (PCR) assays are the most sensitive manner to detect Plasmodium DNA [16, 17] and it detects only viable Plasmodium [18]. Some PCR assays can detect less than 1 parasite $/ \mu \mathrm{L}$ as the technique validated by Cnops et al. [19].

Discrepancies have been often found between microscopy and PCR results for the determination of asymptomatic Plasmodium carriage. For example, Baliraine et al. reported $20.7 \%$ difference $(12.6 \%$ by microscopy and $33.3 \%$ by PCR) [20], Dal-Bianco et al. found $25 \%$ difference $(27 \%$ by microscopy and $52 \%$ by PCR) [21], and May et al. showed $19 \%$ difference ( $48.9 \%$ by microscopy and $67.9 \%$ by PCR) [22].

We conducted this study to assess the weight of asymptomatic carriage of $P$. falciparum in the DRC, based on a highly sensitive RT-PCR assay for malaria parasite identification.

\section{Materials and Methods}

2.1. Study Sites and Participants. We randomly identified health areas within 6 provinces of the DRC with different malaria transmission dynamics: Bolenge in Equateur, Luzizila in Kinshasa, Mweka in Kasai-Occidental, Butembo in Nord-Kivu, Punia in Maniema, and Kapolowe in Katanga Province. This household survey recruited one hundred individuals per province, except for Maniema where only 80 individuals could be included. Every age and sex was taken into account after being given an informed consent by adults and parents/guardians of children. People with fever or other malaria related symptoms were not included in this study. Samples were collected during the period from March to November 2014.
2.2. Blood Collection and DNA Extraction. Five hundred and eighty blood samples were obtained from finger prick and dropped on filter paper (Whatman $3 \mathrm{MM}^{\oplus}$ ) that were dried and stored into individual plastic bags with desiccant. Plasmodium DNA has been extracted using the QIAamp DNA Mini Kit ${ }^{\circledast}$ (Qiagen Benelux, Venlo, Netherlands) according to manufacturer's recommendation. Briefly, 3 circles of approximately $3 \mathrm{~mm}$ diameter were punched out from a blood spot and placed into a $1.5 \mathrm{~mL}$ microcentrifuge tube in which $180 \mu \mathrm{L}$ of buffer ATL was added. The final elution volume was $150 \mu \mathrm{L}$. Each dried blood spot was treated individually into a sterile petri dish to avoid contamination. One negative control (sterile water) was included for each dozen of blood spots treated. DNA was stored at $-20^{\circ} \mathrm{C}$ till further analysis.

2.3. Parasite Identification by Real-Time PCR. A real-time PCR having a sensitivity varying from 0.02 to 0.006 parasites/ $\mu \mathrm{L}$ for human Plasmodium species identification was run, as previously described by Cnops et al. [19]. PCR tests were run on a light cycler 480 instrument $\left(\right.$ Roche $^{\circledast}$ ) and in the presence of positive controls (provided by the Parasitology Unit, Institute of Tropical Medicine, Antwerp, and the Laboratory of Clinical Microbiology, University Hospital of Liège). PCR conditions were as follows: 2 min at $95^{\circ} \mathrm{C}$, followed by 50 cycles of $15 \mathrm{~s}$ at $95^{\circ} \mathrm{C}$ and $60 \mathrm{~s}$ at $60^{\circ} \mathrm{C}$.

2.4. Ethical Considerations. This study has received the ethical approbation of the Ministry of Public Health of the DRC and of the Institutional Committee of the Faculty of Medicine, University of Kinshasa.

\section{Results and Discussion}

P. falciparum was correctly identified in 280 samples (48.2\%) among which 6 infections were mixed ( $P$. falciparum $+P$. malariae). Prevalence of positive samples by age groups is represented in Table 1. The other human Plasmodium species $P$. ovale and $P$. vivax were not found. The real-time PCR cycles thresholds (Ct) vary from 21.72 to 39.23 .

Prevalence of $P$. falciparum infection by province was $51 \%$ for Equateur, $62 \%$ for Kinshasa, 31\% for Kasai-Occidental, $22 \%$ for Nord-Kivu, $63.7 \%$ for Maniema, and $63 \%$ for Katanga, as shown in Figure 1.

\section{Conclusion}

Efforts to control or to eradicate malaria should take into account asymptomatic Plasmodium carriers because elimination of parasites in only symptomatic patients will not be enough as long as the pool of asymptomatic carriers will continue to act as a parasite reservoir [23]. Some researchers have suggested to screen and to treat asymptomatic carriers with an Artemisinin-based combination as part of a surveillance strategy towards malaria elimination [24, 25].

The high prevalence of Plasmodium infections in asymptomatic carriers found in this study stressed the importance 


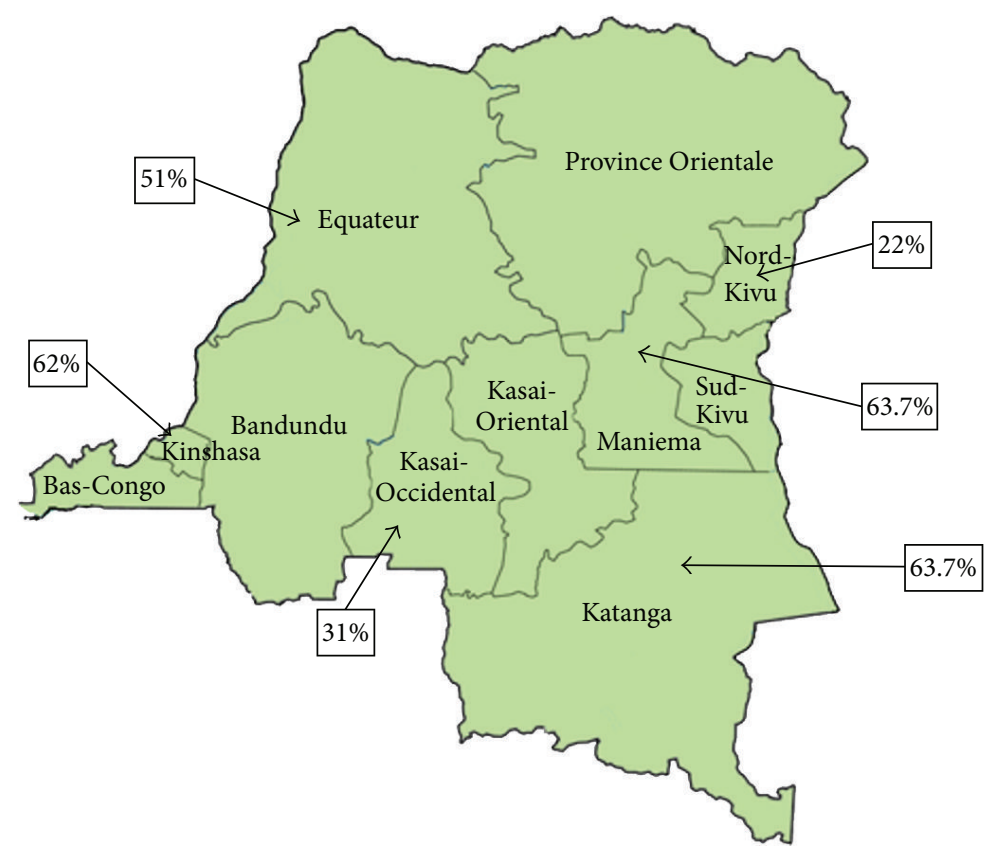

FIGURE 1: Prevalence of P. falciparum infection by collection sites based on a RT-PCR assay.

TABle 1: Prevalence of Plasmodium infections by age groups in the six DRC provinces.

\begin{tabular}{lccccc}
\hline \multirow{2}{*}{ Study sites } & $0-5$ & $6-15$ & $16-59$ & $>60$ & Total \\
& $N(\%)$ & $N(\%)$ & $N(\%)$ & $N(\%)$ & \\
\hline Equateur & $15(29.4)$ & $15(29.4)$ & $21(41.1)$ & $0(0)$ & $\mathbf{5 1}$ \\
Kinshasa & $7(11.3)$ & $10(16.1)$ & $45(72.5)$ & $0(0)$ & $\mathbf{6 2}$ \\
K-occ & $3(9.6)$ & $6(19.3)$ & $20(39.2)$ & $2(6.4)$ & $\mathbf{3 1}$ \\
Kivu & $2(9.1)$ & $5(22.7)$ & $15(68.1)$ & $0(0)$ & $\mathbf{2 2}$ \\
Punia & $4(7.8)$ & $6(11.7)$ & $37(72.5)$ & $4(7.8)$ & $\mathbf{5 1}$ \\
Katanga & $13(20.6)$ & $26(41.2)$ & $21(33.3)$ & $3(4.7)$ & $\mathbf{6 3}$ \\
\hline Total & $\mathbf{4 4 ( 1 5 . 7 )}$ & $\mathbf{6 8 ( 2 4 . 2 )}$ & $\mathbf{1 5 9 ( 5 6 . 7 )}$ & $\mathbf{9 ( 3 . 2 )}$ & $\mathbf{2 8 0}$ \\
\hline
\end{tabular}

K-occ $=$ Kasä̈-occidental

of including this item in malaria control programs by the DRC Ministry of Health.

\section{Conflict of Interests}

The authors declare that there is no conflict of interests regarding the publication of this paper.

\section{References}

[1] N. J. White, S. Pukrittayakamee, T. T. Hien, M. A. Faiz, O. A. Mokuolu, and A. M. Dondorp, "Malaria," The Lancet, vol. 383, no. 9918, pp. 723-735, 2014.

[2] D. L. Doolan, C. Dobaño, and J. K. Baird, "Acquired immunity to malaria," Clinical Microbiology Reviews, vol. 22, no. 1, pp. 1336, 2009.

[3] M. P. Grobusch and P. G. Kremsner, "Uncomplicated malaria," Current Topics in Microbiology and Immunology, vol. 295, pp. 83-104, 2005.
[4] K. P. Day and K. Marsh, "Naturally acquired immunity to Plasmodium falciparum," Immunology Today, vol. 12, no. 3, pp. A68-A71, 1991.

[5] R. W. Snow, J. A. Omumbo, B. Lowe et al., "Relation between severe malaria morbidity in children and level of Plasmodium falciparum transmission in Africa," The Lancet, vol. 349, no. 9066, pp. 1650-1654, 1997.

[6] M. Vafa, M. Troye-Blomberg, J. Anchang, A. Garcia, and F. Migot-Nabias, "Multiplicity of Plasmodium falciparum infection in asymptomatic children in Senegal: relation to transmission, age and erythrocyte variants," Malaria Journal, vol. 7, article 17, 2008.

[7] E. Bottius, A. Guanzirolli, J.-F. Trape, C. Rogier, L. Konate, and P. Druilhe, "Malaria: even more chronic in nature than previously thought: evidence for subpatentparasitemia detectable by PCR," Transactions of the Royal Society of Tropical Medicine and Hygiene, vol. 90, no. 1, pp. 15-19, 1996.

[8] J. F. Trape, A. Zoulani, and M. C. Quinet, "Assessment of the incidence and prevalence of clinical malaria in semi-immune children exposed to intense and perennial transmission," American Journal of Epidemiology, vol. 126, no. 2, pp. 193-201, 1987.

[9] T. Smith, J. D. Charlwood, J. Kihonda et al., "Absence of seasonal variation in malaria parasitaemia in an area of intense seasonal transmission," Acta Tropica, vol. 54, no. 1, pp. 55-72, 1993.

[10] F. P. Alves, L. H. S. Gil, M. T. Marrelli, P. E. M. Ribolla, E. P. Camargo, and L. H. P. Da Silva, "Asymptomatic carriers of Plasmodium spp. as infection source for malaria vector mosquitoes in the Brazilian Amazon," Journal of Medical Entomology, vol. 42, no. 5, pp. 777-779, 2005.

[11] World Health Organization, World Malaria Report, WHO Press, Geneva, Switzerland, 2014, http://www.who.int/malaria/ publications/world_malaria_report_2014/report/en/.

[12] J. R. Matangila, J. Lufuluabo, A. L. Ibalanky, R. A. Inocêncio da Luz, P. Lutumba, and J.-P. Van Geertruyden, "Asymptomatic Plasmodium falciparum infection is associated with anaemia in 
pregnancy and can be more cost-effectively detected by rapid diagnostic test than by microscopy in Kinshasa, Democratic Republic of the Congo," Malaria Journal, vol. 13, article 132, 2014.

[13] V. Maketa, H. Mavoko, R. da Luz et al., "The relationship between Plasmodium infection, anaemia and nutritional status in asymptomatic children aged under five years living in stable transmission zones in Kinshasa, Democratic Republic of Congo," Malaria Journal, vol. 14, no. 1, p. 83, 2015.

[14] Demographic and Health Survey, Democratic Republic of Congo, 2014, http://www.dhsprogram.com/pubs/pdf/FR300/ FR300.pdf.

[15] A. B. Tiono, A. Ouédraogo, A. Diarra et al., "Lessons learned from the use of HRP-2 based rapid diagnostic test in community-wide screening and treatment of asymptomatic carriers of Plasmodium falciparum in Burkina Faso," Malaria Journal, vol. 13, no. 1, article 30, 2014.

[16] G. Snounou, S. Viriyakosol, Xin Ping Zhu et al., "High sensitivity of detection of human malaria parasites by the use of nested polymerase chain reaction," Molecular and Biochemical Parasitology, vol. 61, no. 2, pp. 315-320, 1993.

[17] N. Steenkeste, S. Incardona, S. Chy et al., "Towards highthroughput molecular detection of Plasmodium: new approaches and molecular markers," Malaria Journal, vol. 8, no. 1 , article 86, 2009.

[18] W. Jarra and G. Snounou, "Only viable parasites are detected by PCR following clearance of rodent malarial infections by drug treatment or immune responses," Infection and Immunity, vol. 66, no. 8, pp. 3783-3787, 1998.

[19] L. Cnops, J. Jacobs, and M. Van Esbroeck, "Validation of a fourprimer real-time PCR as a diagnostic tool for single and mixed Plasmodium infections," Clinical Microbiology and Infection, vol. 17, no. 7, pp. 1101-1107, 2011.

[20] F. N. Baliraine, Y. A. Afrane, D. A. Amenya et al., "High prevalence of asymptomatic Plasmodium falciparum Infections in a highland area of western Kenya: a cohort study," Journal of Infectious Diseases, vol. 200, no. 1, pp. 66-74, 2009.

[21] M. P. Dal-Bianco, K. B. Köster, U. D. Kombila et al., "High prevalence of asymptomatic Plasmodium falciparum infection in Gabonese adults," American Journal of Tropical Medicine and Hygiene, vol. 77, no. 5, pp. 939-942, 2007.

[22] J. May, F. P. Mockenhaupt, O. G. Ademowo et al., "High rate of mixed and subpatent malarial infections in southwest Nigeria," The American Journal of Tropical Medicine and Hygiene, vol. 61, no. 2, pp. 339-343, 1999.

[23] G. H. Stresman, A. Kamanga, P. Moono et al., "A method of active case detection to target reservoirs of asymptomatic malaria and gametocyte carriers in a rural area in Southern Province, Zambia," Malaria Journal, vol. 9, no. 1, article 265, 2010.

[24] B. Ogutu, A. B. Tiono, M. Makanga et al., “Treatment of asymptomatic carriers with artemether-lumefantrine: an opportunity to reduce the burden of malaria?" Malaria Journal, vol. 9, no. 1, article 30, 2010.

[25] S. E. Kern, A. B. Tiono, M. Makanga et al., "Community screening and treatment of asymptomatic carriers of Plasmodium falciparum with artemether-lumefantrine to reduce malaria disease burden: a modelling and simulation analysis," Malaria Journal, vol. 10, article 210, 2011. 


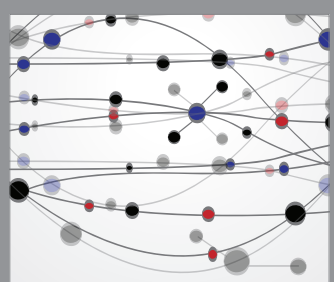

The Scientific World Journal
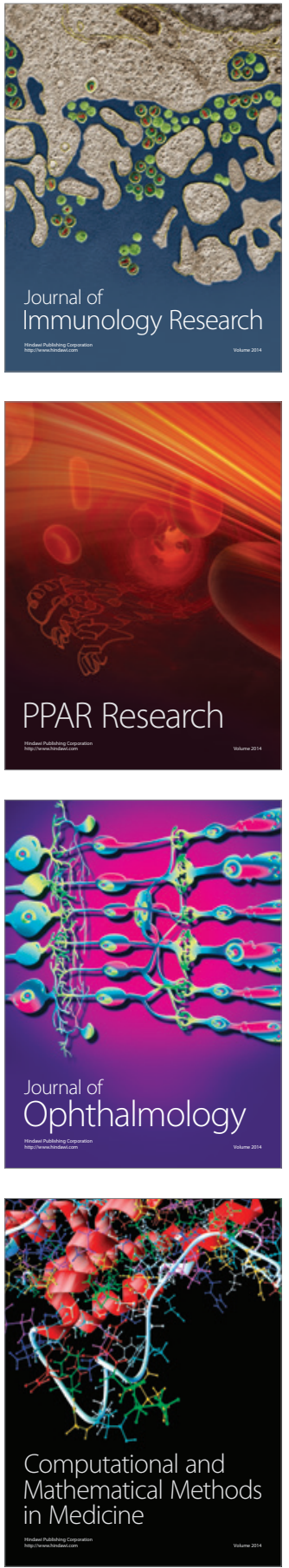

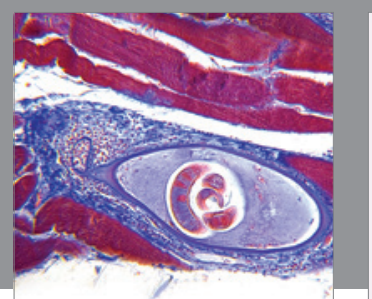

Gastroenterology Research and Practice

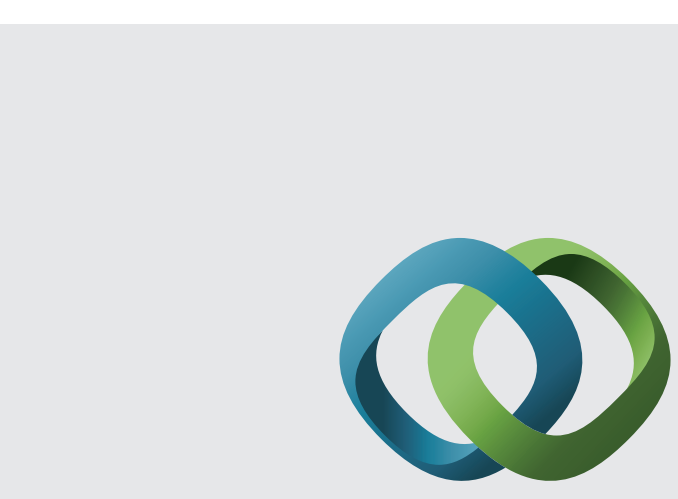

\section{Hindawi}

Submit your manuscripts at

http://www.hindawi.com
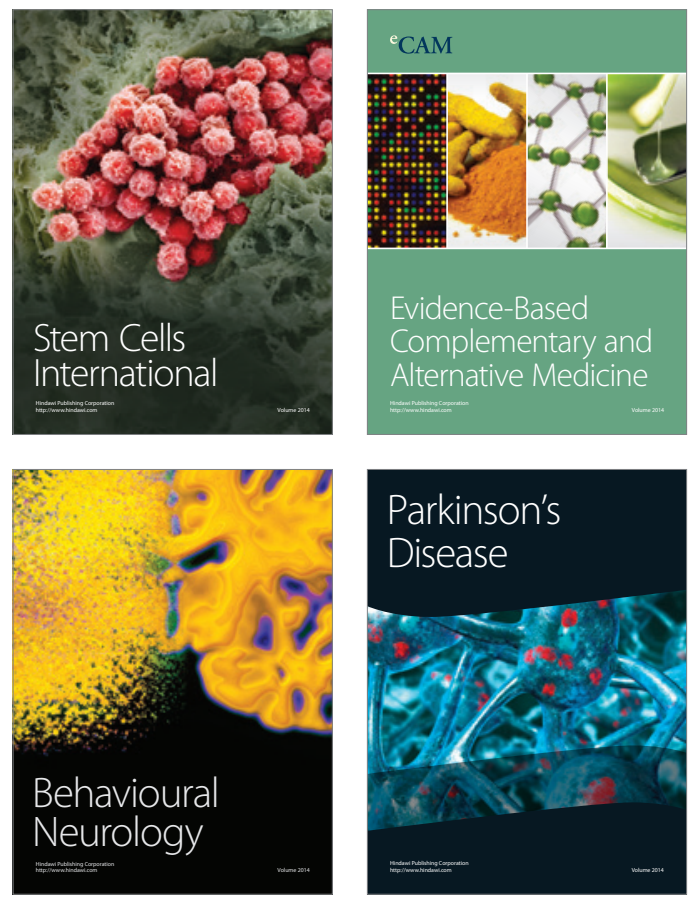
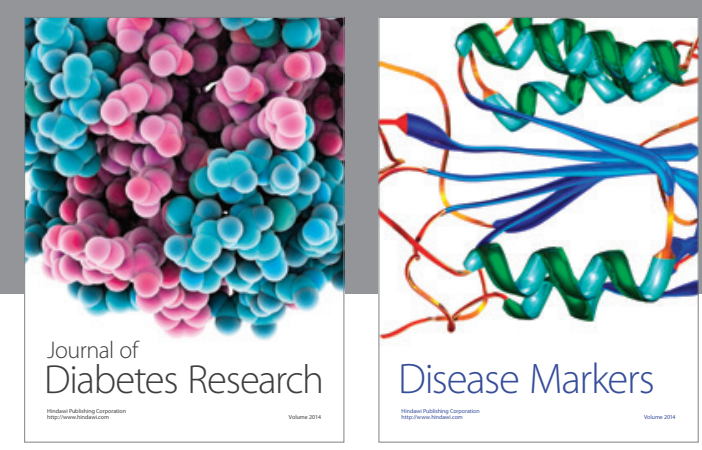

Disease Markers
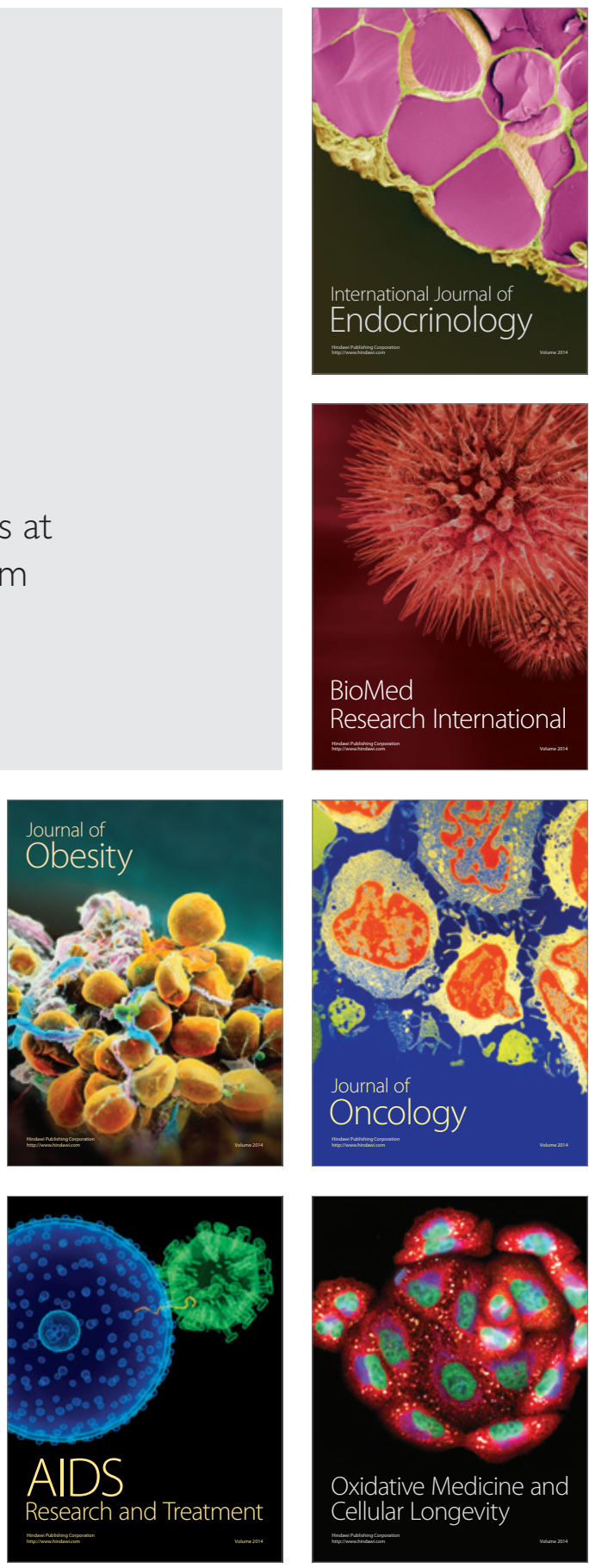